\title{
Impactos de programas nacionais de turismo sobre as instituições e organizações turísticas em municípios do Pará (Brasil)
}

\author{
Impacts of Tourism National Programs on tourist institutions and organizations in \\ cities from Pará State (Brazil)
}

\author{
Cleber Gomes da Silva (SILVA, C. G. da) ${ }^{*}$
}

\begin{abstract}
RESUMO - Neste estudo se analisou a questão de como o poder público em suas diversas esferas brasileiras estabeleceu historicamente estímulos à atividade turística a partir de uma abordagem econômica e seus reflexos na institucionalização do turismo municipal. O Turismo se consolidou na agenda governamental como um vetor de desenvolvimento econômico. Apesar dos seus efeitos na escala local, somente essas ações se direcionaram ao envolvimento dos municípios brasileiros. Desse modo, a metodologia consistiu na seleção de 23 municípios turísticos, considerados prioritários para o governo do estado do Pará (Brasil) e atendidos por programas nacionais. Os resultados desta pesquisa exploratória e descritiva revelaram o perfil institucional e organizacional do turismo, na escala local, a partir de entrevistas e consultas documentais realizadas no período entre 2013 e 2016. Em síntese, permitiu uma reflexão sobre a gestão descentralizada para o desenvolvimento do turismo, no caso dos municípios paraenses. Dessa forma, foram apresentados resultados importantes para o delineamento de ações de melhoria da gestão turística municipal.
\end{abstract}

Palavras-Chave: Turismo; Teoria Institucional; Gestão Municipal.

ABSTRACT - In this study it was analyzed the question of how the public power in its several Brazilian spheres has historically established stimuli to the tourist activity from an economic approach and its repercussions on the institutionalization of municipal tourism. The Tourism has been consolidated in the governmental agenda as a vector of economic development. Despite their effects on the local scale, only these actions were directed to the involvement of Brazilian cities. Thus, the methodology consisted in the selection of 23 tourist cities, considered as priorities for the government of Pará State (Brazil) and assisted by national programs. The results of this exploratory and descriptive research revealed the institutional and organizational profile of tourism, at the local scale, based on interviews and documentary consultation conducted between 2013 and 2016. Then, it allowed a reflection on a decentralized management for the tourism development, in the case of Pará Cities. So, it was presented important results for the design of actions to improve municipal tourism management.

Key words: Tourism; Institutional Theory; Municipal Management.

\footnotetext{
* Formação: Graduação em Turismo (Bacharelado) pela Universidade Federal do Pará (UFPA), Especialização em Gestão Governamental pelo Centro Universitário do Pará/Escola de Governo, Mestrado em Gestão de Recursos Naturais e Desenvolvimento Local na Amazônia pelo PPGEDAM (UFPA) e Doutorando em Geografia (UFPA). Atividade profissional: Já foi servidor das prefeituras de Marituba, Tracuateua e Salinópolis e técnico da Companhia Paraense de Turismo - PARATUR. É servidor efetivo do cargo de técnico em gestão cultural da Secretaria de Estado de Cultura do Pará (SECULT), atualmente cedido à Secretaria de Estado de Turismo (SETUR), ocupando o cargo de Gerente de Estatística e Informação. Docente da Faculdade Pan Amazônica. Tem experiência na área de Turismo e Patrimônio Cultural, com ênfase em políticas públicas, planejamento e elaboração de projetos turísticos e culturais. Endereço físico para correspondência: Rua Jardim Providência, 50, Águas Lindas. CEP 67110440 - Ananindeua - Pará/PA - Brasil. E-mail: gestor.gov@ hotmail.com
} 


\title{
1 INTRODUÇÃO
}

Desde o fim do século XIX e início do século XX, vários teóricos se ocuparam da conceituação de Turismo (OLIVEIRA, 2002). Esse fenômeno social, em sua complexidade, é amplamente discutido por diversas áreas de conhecimento. Araújo e Lobo (2017, p. 3) em seu estudo sobre a Teoria Ator-Rede (ANT) apontam que:

\begin{abstract}
Turismo pode ser considerado um fenômeno complexo, pelos efeitos que produz no espaço ao se promulgar simultaneamente em múltiplas dimensões, o que requer que se tenha uma visão transdisciplinar do fenômeno. Quando um indivíduo decide realizar uma viagem, desde o momento da escolha do destino, até seu retorno ao ponto inicial, uma multiplicidade de elementos de natureza político-social, econômica, cultural e ambiental entram em ação, produzindo ordenamentos territoriais necessários à execução de uma viagem. Consequentemente, são gerados impactos multidimensionais difíceis de serem apreendidos em sua totalidade.
\end{abstract}

Devido à característica multidimensional e reticular do Turismo, muitos trabalhos no Brasil abordaram o tema do planejamento turístico, como visto em autores como Petrocchi (2001), Boullón (2002), Hall (2004), Beni (2006) entre outros. Arrilaga (1976, p. 25) reforçou a existência tanto do caráter multidimensional quanto das inúmeras relações produzidas pelo Turismo:

Em sua globalidade, não está formado só pelas pessoas que viajam e pelos bens e serviços que se lhes oferecem e que elas utilizam; entre uns e outros, surge uma série de relações e situações de fato de caráter econômico, sociológico e até político.

Outras importantes contribuições teóricas a respeito do Turismo podem ser destacadas. Cuervo (1967) conceitua como conjunto de relações, serviços e instalações gerados em virtude de certos deslocamentos humanos. Para Molina (1997) o Turismo é um sistema composto por superestrutura, demanda turística, infraestrutura, atrativos, equipamentos, instalações e comunidades receptoras. Leiper (1990) considera em seu estudo que envolve áreas geradoras, turistas, regiões de trânsito, regiões receptoras e a indústria turística. No entanto, a abordagem sistêmica de Hall (2004), expõe a dinâmica das relações entre homem e meio ambiente e dos processos de planejamento que envolvem o papel do Estado nos sistemas turísticos, devendo coordenar, planejar, legislar, empreender, incentivar e promover o turismo social e a proteção do interesse público. 
Apesar da discussão no campo teórico, em 1991, a Organização Mundial de Turismo (OMT) definiu o turismo como "as atividades de pessoas que viajam para lugares afastados de seu ambiente usual ou que neles permanecem por menos de um ano consecutivo, a lazer, a negócios ou por outros motivos" (OMT, 2003, p. 20).

Como oportunidade econômica, o turismo é um fenômeno de consumo e ao mesmo tempo de produção. Alguns autores sustentam a existência de um produto turístico. Lage e Milone (1996, p. 51) mencionam ser "o conjunto de bens e serviços relacionados a toda e qualquer atividade turística". Para Santos e Kadota (2001, p. 25) “o produto turístico é simplesmente o produto consumido por um turista". Entretanto, Boullón (2006, p. 29), argumenta o turismo não é uma indústria.

\footnotetext{
Queda claro, pues, que el turismo es una forma de consumir, algo así como um canal al que confluye uma demanda especial de muchos tipos de bienes y servicios elaborados por otros sectores, más el consumo de algunos servicios especialmente diseñados para satisfazer necesidades próprias de los viajeros. Por tanto, el turismo pertence al sector terciário, y no al secundario, como debería ser para que se le pudiera catalogar como perteneciente a la industria.
}

Partindo dessa abordagem mais econômica este estudo fundamenta-se essencialmente em uma Teoria Institucional, especialmente na proposição de Douglass C. North (1995). De acordo com esse autor, a evolução econômica e histórica de uma sociedade é condicionada pela formação e evolução de suas instituições. Essas instituições são normas cuja função principal é reduzir incertezas, estabelecendo uma estrutura estável, sendo informais como acordos, códigos de conduta e normas de comportamento e formais como leis estruturais e contratos escritos.

Outro conceito importante para esta pesquisa é o de organizações. Conforme North (1995) as organizações incluem corpos políticos, econômicos, sociais e órgãos educativos. Estes por sua vez são grupos de indivíduos enlaçados por alguma identidade e objetivos comuns. A sobrevivência ou evolução das organizações é fundamentada por instituições.

Considerou-se o enfoque econômico e a necessidade de compreender o momento institucional em que se encontravam os 23 municípios pesquisados: Belém, Bragança, Salinópolis, Curuçá, Tracuateua, Maracanã, Marapanim, Paragominas, São Caetano de Odivelas, Vigia, Barcarena, Tucuruí, Marabá, Cametá, Conceição do 
Araguaia, Parauapebas, Altamira, Soure, Salvaterra e Ponta de Pedras, Santarém, Belterra, Oriximiná.

Nesta pesquisa se buscou responder a seguinte questão: quais seriam os reflexos dos programas estabelecidos pela Política Nacional de Turismo sobre a ação de governos locais para o desenvolvimento turístico no Pará?

Desse modo, a escala local é tomada empiricamente nesta pesquisa na esfera administrativa municipal, observada em suas particularidades. Assim, abordou-se a materialização do modelo de desenvolvimento turístico do país, inicialmente pela descentralização promovida pelo Programa Nacional de Municipalização do Turismo (PNMT) e o Programa de Regionalização do Turismo (PRT), conforme estudo bibliográfico e documental.

A partir dessa contextualização, foi realizada uma análise da situação da gestão pública municipal de turismo, nos municípios pesquisados, observando a interveniência da gestão estadual. Os resultados e discussão são organizados em duas partes. $\mathrm{Na}$ primeira desenvolve-se um panorama dessa política desde os anos de 1950 e no segundo momento se apresenta os principais impactos sobre as instituições formais e as organizações municipais de Turismo.

\section{METODOLOGIA}

Este artigo resulta de um estudo exploratório e descritivo sobre o desenvolvimento institucional do turismo em 23 municípios paraenses. Trata-se de um "levantamento de fontes secundárias, estudo de casos selecionados e observação informal"(DENCKER, 1998, p. 128).

Conforme Triviños (2011), os estudos descritivos podem ser denominados de estudo de caso, pois têm como objetivo aprofundar a descrição de determinada realidade, observando-se todas as variáveis e seus resultados são válidos só para o caso que se estuda. Essa escolha metodológica pode ser apoiada por Yin (2001), para quem esse tipo de estudo investiga um fenômeno contemporâneo em seu contexto de vida real. É uma categoria de pesquisa cujo objeto é uma unidade que se analisa aprofundadamente. 
Entre as estratégias adotadas para o estudo, realizou-se pesquisa bibliográfica; documental e survey. Sobre esse aspecto, Martins e Theóphilo (2009) explicam que a pesquisa bibliográfica é necessária para a condução de qualquer pesquisa científica, procurando conhecer, analisar e explicar contribuições sobre determinado assunto. A pesquisa documental é característica de estudos que utilizam documentos dos mais variados tipos como fonte de dados. Lakatos e Marconi (2009) incluem nesta categoria documentos oficiais, publicações parlamentares, documentos jurídicos e fontes estatísticas.

A pesquisa bibliográfica ofereceu subsídios para construção do referencial teórico do trabalho. Na pesquisa documental, coletaram-se dados referentes às políticas públicas de Turismo, em leis e outros documentos oficiais. A coleta de dados culminou na realização do levantamento de informações da gestão municipal de Turismo.

A amostra foi delineada com a escolha do tipo não-probabilística por conveniência. É representada por 23 municípios considerados prioritários da Política Estadual de Turismo no Pará, do universo de 144 municípios paraenses. Tendo em vista o alcance do objetivo da pesquisa foi realizada uma consulta aos gestores públicos e técnicos responsáveis pelo órgão municipal de turismo, por meio de envio de questionários, aliada a pesquisa documental, com os dados sendo obtidos entre 2015 e 2016.

A análise dos resultados decorreu identificação de respostas positivas sobre quatro aspectos da institucionalização da gestão municipal: organismos de gestão, os instrumentos jurídicos, planejamento e as ações da gestão municipal. Para operacionalização da pesquisa e tratamento dos dados, as questões correspondentes aos organismos de gestão referiram-se aos espaços da administração pública direta, indireta ou colegiados com atribuições de desenvolvimento turístico municipal e os que garantiam a decisão de atores.

Sobre os instrumentos jurídicos, observaram-se os princípios da legalidade da administração pública, na forma das leis de criação dos organismos de gestão e da autorização das ações municipais. Como essa dimensão não necessariamente reflete o impacto direto da ação, mas propriamente a autorização de intervenções públicas, foi necessário levantar informações sobre as ferramentas de pesquisa e planejamento, assim 
como as principais ações de intervenção pública e suas condições técnicas para alcance de um resultado planejado nos municípios pesquisados.

\section{RESULTADOS E DISCUSSÃO}

Os resultados desta pesquisa foram organizados inicialmente pela apresentação dos principais programas nacionais de turismo. Posteriormente, apresenta-se o cenário da gestão municipal de turismo de 23 municípios analisados, contextualizada na sua relação com gestão estadual no Pará.

\subsection{PROGRAMAS NACIONAIS DE TURISMO}

A discussão sobre a importância econômica do Turismo no Brasil encontra antecedentes importantes na década de 1950. De acordo com Carvalho (2000) nesse período foi criada a Divisão de Turismo, vinculada ao Departamento de Imprensa e Propaganda da Presidência da República, com a finalidade de fiscalizar as atividades de agências de viagens, sendo que em 1958 criou-se a Comissão Brasileira de Turismo Combratur, durando até 1962, quando foi extinta.

Na década de 1960, as propostas de desenvolvimento do turismo no Brasil foram incluídas entre as estratégias econômicas do país. Em que pese essas primeiras iniciativas, o principal antecedente histórico do sistema jurídico e da política nacional de turismo é o Decreto $\mathrm{n}^{\circ} 55$ de 18 de novembro de 1966, que criou o Conselho Nacional de Turismo e a Empresa Brasileira de Turismo - EMBRATUR (BOITEUX, 2003, p. 23). Essa política foi incrementada em 1970 com a criação do Fundo Geral de Turismo, FUNGETUR, através de Decreto-lei n ${ }^{\circ} 1.191$ de 27 de outubro de 1971, e regido pelo Decreto-lei $\mathrm{n}^{\mathrm{o}} 1.439$, de 30 de dezembro de 1975, tendo por objetivo prover recursos para o financiamento de empreendimentos, obras e serviços de finalidade ou de interesse turístico (MAMEDE, 2002. p. 49).

No final da década de 1970, ocorreram alguns avanços na questão da definição da área de abrangência do setor. A lei 6.505 de 13 de dezembro de 1977 do ainda Ministério da Indústria, do Comércio e do Turismo definiu como serviços turísticos: meios de 
hospedagem, restaurantes de turismo, acampamentos turísticos, agências de turismo, transportadoras turísticas, empresas que prestavam serviços aos turistas e viajantes (BOITEUX, 2003). Essa definição enquadrou claramente a atividade no setor de serviços.

A consolidação do Turismo na agenda pública aconteceu na Constituição Federal de 1988, cujo artigo 180 determinou que a União, estados, Distrito Federal e municípios promoveriam e incentivariam o turismo como fator de desenvolvimento social e econômico (MAMEDE, 2002). Ao ser reestruturada em 1991, a Embratur, antes Empresa Brasileira de Turismo transformou-se no atual Instituto Brasileiro de Turismo, autarquia com competências sobre a Política Nacional de Turismo (BADARÓ, 2003). As diretrizes dessa política: a prática do turismo como forma de valorização e preservação do patrimônio natural e cultural e a valorização do homem como destinatário do desenvolvimento turístico foram delineadas em 1992, no artigo $2^{\circ}$ do Decreto Federal 448 (BOITEUX, 2003).

A partir da década de 1996, destaca-se uma nova estratégia de descentralização em direção à ação municipal, através da implementação do Programa Nacional de Municipalização do Turismo - PNMT. De acordo com Boiteux (2003, p. 41), "foi também um passo importante na municipalização do turismo, embora se apresentasse como uma receita de bolo, com etapas pré-definidas sem levar em consideração as peculiaridades locais".

\footnotetext{
A política nacional do turismo implantada pelo governo Fernando Henrique Cardoso, para vigorar no período de 1996-1999, apresenta os seguintes objetivos: a) a ordenação das ações do setor público, orientando o esforço do Estado e a utilização dos recursos públicos para o bem-estar social; b) a definição de parâmetros para o planejamento e a execução das ações dos governos estaduais e municipais; c) a orientação referencial ao setor privado (NÓBREGA, 2007, p. 47).
}

O PNMT foi implementado entre 1995 e 2001, em 1.081 municípios e utilizava uma metodologia participativa de planejamento, desenvolvida por uma agência governamental alemã, a Sociedade Alemã de Cooperação Técnica (GTZ) (EMBRATUR, 2002). Esses municípios recebiam oficinas de sensibilização, capacitação e planejamento, voltadas para a criação de conselhos municipais, fundos de turismo e elaboração de planos municipais. Sansolo (2013) explica que a metodologia 
adotada foi o ZOOP (Ziel Orientierte Projekt Planung), como ferramenta de mobilização.

Embora o PNMT fosse um dos principais programas federais, os principais investimentos nesse período, estão relacionados a outro Programa, o PRODETUR (Programa de Ação para o Desenvolvimento do Turismo), instituído pela Portaria $n^{\circ} 1$, de 29 de novembro de 1991, por ação conjunta da Superintendência do Desenvolvimento do Nordeste-SUDENE e o Instituto Brasileiro do Turismo - Embratur (CRUZ, 2001). Conforme Paiva (2010) esses investimentos concentraram-se no Nordeste, desde 1994 até 1999, sendo privilegiadas na fase I: a infraestrutura de saneamento básico (água e esgoto) e de suporte ao turismo, instalação ou ampliação de aeroportos, urbanização de áreas turísticas, centro de convenções, recuperação do patrimônio histórico, bem como um aquecimento da economia das localidades turísticas. De acordo com essa autora, os resultados satisfatórios do Prodetur I e o cenário de sucesso motivaram a concepção do Prodetur II, em1994, tendo negociações iniciadas em 1999 e sucedidas por estratégias mais racionais em substituição às anteriores, com a disponibilização de US\$ 800 milhões.

Todavia, muitos municípios considerados turísticos não apresentaram a adequação institucional necessária para a efetiva articulação desse programa, como argumenta Queiroz (1995, p. 167):

O Prodetur Nordeste desde sua concepção inicial pressupôs a articulação entre órgãos dos poderes públicos federal, estadual e municipal e a iniciativa privada. A pretendida articulação institucional com as prefeituras terminou por constituir-se no elo mais fraco da cadeia.

Conforme demonstra Abrúcio (2005), nesse período, o repasse de recursos era condicionado à participação e fiscalização da sociedade, conforme previsto na Constituição de 1988, por meio da criação de conselhos de políticas públicas, como condicionante para o recebimento de certas transferências. Embora, "o caráter democrático da descentralização, mais do que o aspecto fiscal foi a tônica dessa política" (ABRÚCIO, 2005, p. 53).

Não obstante, a partir de 2003 inicia-se a implementação do principal instrumento de planejamento do turismo no nível federal, sendo lançado o Plano Nacional de Turismo de 2003 a 2016, tendo como objetivos gerais: Desenvolver o 
produto turístico brasileiro com qualidade, contemplando diversidades regionais, culturais e naturais do país e Estimular e facilitar o consumo do produto turístico brasileiro nos mercados nacional e internacional e como principais metas: criar condições para gerar 1.200.000 novos empregos e ocupações; aumentar para 9 milhões o número de turistas estrangeiros no Brasil; gerar 8 bilhões de dólares em divisas; aumentar para 65 milhões a chegada de passageiros nos voos domésticos e ampliar a oferta turística brasileira, desenvolvendo no mínimo três produtos de qualidade em cada Estado da Federação e Distrito Federal (BRASIL, 2003).

O Plano foi revisado para o período de 2007 a 2010 com o compromisso de dar continuidade nas ações que estavam em curso, entretanto, apresentava contribuições do turismo ao Programa de Aceleração do Crescimento 2007/2010, alinhando as suas respectivas ações. ( BRASIL, 2007). Outra versão intitulada de "O turismo fazendo muito mais pelo Brasil”, para o período de 2013 a 2016, adequando-se ao período de realização de grandes eventos esportivos internacionais como a Copa das Confederações, Copa do Mundo de 2014 e as Olimpíadas de 2016, no Rio de Janeiro, apresentou a necessidade de consolidar o Sistema Nacional de Turismo, reconhecendo que era necessário aperfeiçoar a interlocução e a qualificação institucional, a partir das unidades federadas, com as regiões e os municípios que compunham a estratégia de regionalização, estabelecendo sinergias, rotinas e critérios que permitissem avançar na prática da gestão compartilhada de forma consensual e coletiva (BRASIL, 2013).

Nesse aspecto, desde 2003, o destaque do Plano, em suas versões sempre foi o Programa de Regionalização do Turismo - PRT, deixando o foco na gestão municipal e parte para integração desses entes através de regiões turísticas.

\footnotetext{
A Regionalização do turismo é um modelo de gestão de política pública descentralizada, coordenada e integrada, baseada nos princípios da flexibilidade, articulação, mobilização, cooperação intersetorial e interinstitucional e na sinergia de decisões (BRASIL, 2004, p. 11).
}

A gestão do PRT foi caracterizada pela instalação de níveis de coordenação nas esferas federal, estadual e chega à esfera municipal. Os roteiros turísticos (intermunicipais), produzidos tentaram contemplar a integração de municípios e dispondo de uma novidade: a institucionalização de colegiados regionais, denominadas 
de instâncias de governança regionais, que congregassem representantes do poder público, setor privado e sociedade civil, no âmbito dos roteiros (BRASIL, 2004).

Em 2008, a partir do projeto de lei 3.118/08 com o objetivo de instituir a Lei do Turismo, sendo promulgado em 17 de setembro de 2008 como lei 11.771, passando, então, o Brasil a ter uma legislação própria para regular a atividade no Brasil, contribuir para seu planejamento e definir a política nacional do turismo. (DE OLIVEIRA, 2009).

Pelo texto da Lei 11.771 (BRASIL, 2008) passou a ser considerado como Turismo todas as atividades realizadas por pessoas físicas durante viagens e estadas em lugares diferentes de seu entorno habitual por um período inferior a 1 (um) ano, com a finalidade de lazer, negócios e outros, devendo gerar movimentação econômica, trabalho, emprego, renda e receitas públicas. Também instituiu o Sistema Nacional de Turismo, composto pelos seguintes órgãos e entidades: I - Ministério do Turismo; II Embratur - Instituto Brasileiro de Turismo; III - Conselho Nacional de Turismo; e IV Fórum Nacional de Secretários e Dirigentes Estaduais de Turismo, podendo ainda integrar o Sistema os fóruns e conselhos estaduais de turismo; os órgãos estaduais de turismo; e as instâncias de governança macrorregionais, regionais e municipais. Segundo a lei, O Ministério do Turismo coordenaria os programas de desenvolvimento do turismo, em interação com os demais integrantes.

\subsection{A GESTÃO DE TURISMO NOS MUNICÍPIOS PRIORITÁRIOS}

No Estado do Pará a gestão pública do turismo foi estabelecida mais evidentemente com a criação da Companhia Paraense de Turismo - Paratur, sociedade de economia mista pertencente à administração indireta do governo, criada pela Lei Estadual $n^{\circ} 4468$ de 9 de dezembro de 1971 e regulamentada pelo Decreto $n^{\circ} 8026$ de 12 de julho de 1972. Além dessa estatal foi criado em 2003, o Fórum de Desenvolvimento Turístico do Estado do Pará - Fomentur, criado pelo Decreto Estadual $\mathrm{n}^{\circ}$ 0221, de 26 de junho, como órgão colegiado consultivo, propositivo e mobilizador (PARÁ, 2011).

Em 28 de dezembro de 2011, por meio da lei estadual $n^{\circ} 7.593$, foi criado o Sistema de Gestão Estadual de Turismo, composto pela Paratur, Fomentur e pela Secretaria de Estado de Turismo - Setur (PARÁ, 2011). De acordo com a lei de criação, a 
missão da Setur é coordenar o processo de concepção de implementação da política de desenvolvimento do turismo no Estado, de forma sustentável e integrada, tornando o Pará um destino competitivo. No aspecto do planejamento, a Secretaria é responsável pela execução do Plano Estratégico de desenvolvimento de turismo do Estado do Pará - 2012 a 2020. Todavia, em 30 de dezembro de 2014 a Paratur foi extinta pela lei $\mathrm{n}^{\circ} 8.093$. (PARÁ, 2014).

No que se refere ao planejamento do governo do Estado o Pará, em 2001 ações propostas no Plano de Desenvolvimento Turístico do Estado do Pará (CASTRO; NASCIMENTO, 2010). O objetivo principal era de converter o Pará em um destino turístico preferencial para o mercado nacional e internacional, mediante um desenvolvimento turístico competitivo e sustentável (PARÁ, 2001). Esse processo de planejamento foi retomado em 2011 com o lançamento do Plano Estratégico de Turismo do Pará - Ver-o-Pará (2011), oferecendo novas diretrizes da política pública de investimentos para o setor de turismo, tendo como visão de futuro tornar o Pará destino líder da Amazônia até 2020.

As ações do planejamento turístico observam o ordenamento territorial ${ }^{1}$ estadual em vigor, sendo articulado com base em regiões de integração que se agrupam em polos turísticos, onde se destacam os municípios prioritários para investimentos turísticos (PARÁ, 2008; FAPESPA, 2016). Essa organização pode ser visualizada no Quadro 1:

QUADRO 1 - ORDENAMENTO TURÍSTICO DO PARÁ

\begin{tabular}{|c|c|c|}
\hline POLOS TURÍSTICOS & REGIÕES DE INTEGRAÇÃO & $\begin{array}{l}\text { MUNICÍPIOS } \\
\text { PRIORITÁRIOS }\end{array}$ \\
\hline Belém & Região Metropolitana & Belém \\
\hline Amazônia Atlântica & $\begin{array}{l}\text { Região Guamá, Região Rio } \\
\text { Capim e Região do Caeté }\end{array}$ & $\begin{array}{l}\text { Bragança, Curuçá, Maracanã, } \\
\text { Marapanim, Salinópolis, São } \\
\text { Caetano de Odivelas, Tracuateua, } \\
\text { Paragominas e Vigia. }\end{array}$ \\
\hline Araguaia Tocantins & $\begin{array}{l}\text { Região Araguaia, Região Carajás, } \\
\text { Região Tocantins e Região Lago } \\
\text { de Tucuruí }\end{array}$ & $\begin{array}{l}\text { Barcarena, Cametá, Marabá, } \\
\text { Parauapebas, Tucuruí } \\
\text { Conceicãa do Araguaia. }\end{array}$ \\
\hline Tapajós & $\begin{array}{l}\text { Região do Baixo Amazonas e a } \\
\text { Região Tapajós }\end{array}$ & Santarém, Belterra e Oriximiná \\
\hline Marajó & Região Marajó & $\begin{array}{l}\text { Soure, Salvaterra e Ponta de } \\
\text { Pedras }\end{array}$ \\
\hline Xingu & Região Xingu & Altamira \\
\hline
\end{tabular}

FONTE: Elaborado pelo autor a partir da legislação turística do Estado do Pará.

\footnotetext{
${ }^{1}$ Decreto estadual no 1.066 em 19 de junho de 2008. (PARÁ, 2008).
} 
Apesar da implementação de um processo de planejamento turístico estadual ser recente, a participação nos programas de descentralização do turismo promovidos pelo governo federal datam de 1997, quando o Pará aderiu ao PNMT. De acordo com Sansolo (2013) no Pará 13 municípios, participaram das oficinas de $1^{\mathrm{a}}$ fase, 49 municípios participaram das oficinas de $2^{\mathrm{a}}$ fase e 21 participaram das oficinas de $3^{\mathrm{a}}$ fase.

Com base no levantamento realizado pela pesquisa, verificou-se a participação de 18 dos municípios em seus fóruns regionais, sendo que apenas 12 estavam possuindo um Conselho Municipal em atividade regular, apesar de que 16 dos municípios declararam possuir lei que criava seu Conselho Municipal. Essa condição compromete a legitimidade de ações que envolvem a maioria dos investimentos em turismo e outras deliberações. Os 23 municípios declararam possuir órgão específico para o turismo, todavia 19 não possuíam lei ou decreto com atribuições do órgão municipal de turismo. Outro problema a ser analisado é o fato de que mesmo aqueles que estavam possuindo um órgão específico para tratar da pasta, somente em 4 se apresentava quadro técnico com formação superior em turismo, espaço próprio, computadores e veículos.

O estabelecimento de uma política fiscal é importante para ocorrer avanços no cadastro e acesso à informação sobre os prestadores de serviços no município, vinculando a emissão da licença de funcionamento. Esse desprezo pelo cadastro de informações sobre as empresas de turismo ficou representado por apenas 3 municípios com lei que estabelecia cadastro de empresas turísticas tendo impacto direto na própria arrecadação municipal de impostos incidentes sobre o turismo, no qual se inclui essencialmente o Imposto sobre Serviços (ISS) ou de taxas de turismo. A instrumentalização adequada de uma política tributária para as atividades características do turismo municipal, essencialmente a hotelaria, o agenciamento, o transporte, o lazer e a alimentação estava permitindo o início de um debate sobre a possibilidade de adoção de incentivos fiscais, criação de fundos municipais para estimular novos investimentos públicos ou privados e manutenção de atividades de desenvolvimento do turismo.

Nesse sentido, verificou-se que 10 dos municípios pesquisados aprovaram sua lei de criação do fundo de turismo e nenhum deles estava regulamentado, sendo que 3 declararam possuir alguma lei de incentivo fiscal.

Em se tratando dos instrumentos de gestão, verificou-se que 17 dos municípios contavam com Plano Diretor Urbano. Nesse caso, relaciona-se diretamente com o 
ordenamento da aplicação de investimentos e da estratégia de ocupação das principais zonas municipais de interesse turístico. É muito importante considerar que atividade turística envolve diretamente o uso do solo urbano como centro logístico necessário ao turismo, bem como a disponibilidade de aproveitamento do patrimônio cultural e natural. Por outro lado, apenas 7 declararam já ter elaborado um plano de desenvolvimento turístico. Essa condição denota a falta de planejamento municipal para o turismo, sendo que as ações de governo tendem a ser descontextualizadas dos problemas que envolvem as atividades turísticas no seu contexto empírico.

No que se refere ao orçamento municipal 17 declararam ter programas no PPA, entretanto. Entretanto, identificou-se que apenas 12 possuíam orçamento específico no exercício fiscal correspondente ao ano de realização da pesquisa. Outra condição identificada foi a inexistência de investimentos por meio do uso de recursos de fundo municipal de turismo.

Não obstante, questões fundamentais como acesso à internet e a realização de inventários turísticos, refletem a capacidade da gestão da informação. Nesse aspecto, sendo que todos os municípios pesquisados adotavam esses instrumentos. Em relação ao estudo da demanda, 20 já haviam realizado alguma pesquisa de perfil de seu turista, contudo, sem frequência necessária para atualização anual dos seus registros. Notou-se que ao contrário do conhecimento do público-alvo, apenas 10 apresentaram calendário de eventos turísticos definido. Isso denota a falta de uma estratégia consolidada de marketing e atração de fluxos.

Conforme foi possível analisar, a principal estratégia de ações do setor público municipal concentrou-se na realização de eventos por 9 dos municípios estudados. Os serviços relacionados ao atendimento básico do setor empresarial, que se reflete na capacidade de facilitar o investimento foi uma estratégia desenvolvida por menos da metade dos municípios.

Considerando todos os dados analisados, foi possível identificar que os municípios com eficiência à época, foram Conceição do Araguaia, Santarém, Bragança, Tucuruí, Barcarena e Salinópolis. Tais municípios apresentaram-se em situações mais efetivas de gestão. No entanto, cabe ressaltar que em relação a eficiência dos instrumentos, seriam necessários novos estudos de aprofundamento sobre a questão da qualidade institucional do Turismo municipal. 


\section{CONSIDERAÇÕES FINAIS}

Concluiu-se, a partir do estudo apresentado, que a capilaridade dos programas nacionais apresentou rebatimento em parte da ação municipal, mas não suficiente para consolidar as instituições e organizações turísticas locais. Apesar da interveniência do governo estadual, no sentido de promover um planejamento estratégico e articular ações do governo federal no âmbito local, de acordo com os resultados analisados a partir das informações coletadas nos municípios considera-se não haver efetividade do sistema de gestão.

Na concepção institucionalista (NORTH, 1995) a evolução do mercado é determinada por instituições capazes de reduzir custos de transação, garantir proteção e estabilidade dos contratos privados, diminuindo incertezas; assim como, a uma limitação do poder centralizador e aumento da autonomia das cidades. Em caso contrário, também pode tolher permanentemente seu desenvolvimento. Com base nessa teoria, o desenvolvimento econômico do Turismo também depende inicialmente do desempenho das instituições e organizações. Sansolo (2013), analisando os impactos do Programa de Municipalização do Turismo argumentou:

\footnotetext{
Pode-se dizer que o principal resultado alcançado foi a sensibilização dos municípios para o turismo como vetor de desenvolvimento econômico. Entretanto, uma avaliação da capacidade institucional dos municípios para o planejamento, implementação, monitoramento e avaliação de políticas, programas e projetos pode expor a fragilidade atual da maioria dos municípios brasileiros no que se refere ao setor turístico (SANSOLO, 2013, p. 112).
}

Nesse sentido, o cenário de desarticulação institucional pode gerar descontinuidade no processo de planejamento e produzindo um Turismo com repercussões negativas nos resultados finais. Como reforçou Oliveira (2002, p. 47) "A presença dos turistas leva o poder público a adaptar seu comportamento às novas necessidades. [...] Caso contrário, existirá apenas a presença do turista. Nada mais”.

O turismo está inserido diretamente no setor de serviços e comércio, de responsabilidade de estados e municípios. Por outro lado, para que ações da gestão do turismo convertam recursos em benefícios locais é imprescindível o aprimoramento político, institucional e técnico desse sistema. Vignati (2012) destaca a participação do Estado e da sociedade civil como colaboradores e beneficiários do processo de 
desenvolvimento turístico, assim como o setor privado é responsável pela dinamização econômica e comercial por meio de um ambiente seguro para investimentos para potencial rentabilidade de curto, médio e longo prazo.

O Turismo deve ser compreendido como algo inerente à vida em sociedade. Entretanto, tentou-se levantar neste estudo que ainda pareceu muito distante uma política consolidada nos três níveis de governo. Considerou-se ter ficado evidente o distanciamento entre o modelo pensado para o turismo no Brasil e as limitações no nível municipal.

O estudo revelou que o princípio da legalidade foi parcialmente atendido pelos municípios. Ressalta-se que o fato de existir uma lei que cria um conselho municipal ou fundo de turismo, não necessariamente representa regularidade das atividades. Além disso, o sucesso das ações municipais estava dependendo ainda, da capacidade de planejamento público e de investimentos do tesouro municipal, por meio do orçamento público.

É essencial que ocorra o alinhamento entre o Plano de Turismo e o Plano Plurianual dos municípios, pois isso reflete as estratégias gerais de investimentos por meio de programas e projetos de expansão do setor. Se a ação governamental tem um enfoque econômico é fundamental que o fluxo turístico deva ser planejado e monitorado. Em todos seus níveis de governo, os municípios também devem conduzir, orientar e normatizar a rede de serviços turísticos por uma base de limitações e incentivos que possibilitem uma melhor dinâmica do setor, alinhadas em seus instrumentos disponíveis a outras esferas de governo.

De forma geral, toda a gestão de turismo deve ser aperfeiçoada, no que se refere ao fluxo de informações, o estímulo à boa governança, a facilitação de crédito às atividades, especialmente de iniciativas cooperativas ou associativas. Importa também haver uma gestão integrada, entre os níveis de governo, corretamente institucionalizada, atuante, coordenada e eficiente. Este trabalho consistiu no resultado de uma abordagem que, sobretudo, estabelece uma relação entre os programas nacionais e a ação municipal. 


\section{REFERÊNCIAS}

ABRÚCIO, F. L. A coordenação federativa no Brasil: a experiência do período FHC e os desafios do governo Lula. Revista de Sociologia e Política, Curitiba, n. 24, p. 41-67, Jun. 2005.

ARAUJO, G. A. de; LOBO, C. Teoria ator-rede e análise do turismo: um novo paradigma? Revista Turismo \& Sociedade, Curitiba, v. 10, n. 2, p. 1-14, Junho, 2017.

ARRILLAGA, J. I. de. Introdução ao estudo do turismo. Rio de Janeiro: Editora Rio, 1976.

BADARÓ, R. A. de L. Direito do turismo: legislação no Brasil e no exterior. São Paulo: Editora Senac São Paulo, 2003.

BENI, M. C. Política e Planejamento de Turismo no Brasil. São Paulo: Aleph, 2006 (Série Turismo).

BOITEUX, B. Legislação do turismo: tópicos de direito aplicados ao turismo. Rio de Janeiro: Campus, 2003.

BOULlÓN, R. C. Planificación del espacio turístico. 4. ed. México: Trillhas, 2006.

BRASIL. Ministério do Turismo. Plano Nacional de Turismo 2007-2010 - uma viagem de inclusão. Brasília: Ministério do Turismo, 2007.

Ministério do Turismo. Plano Nacional de Turismo 2013-2017 - O turismo fazendo muito mais pelo Brasil. Brasília: Ministério do Turismo, 2013.

Ministério do Turismo. Plano Nacional do Turismo: diretrizes, metas e programas (2003-2007). Brasília: Ministério do Turismo, 2003.

Programa de Regionalização do Turismo - Roteiros do Brasil. diretrizes políticas. Brasília: Ministério do Turismo. 2004.

Lei $\mathbf{n}^{\circ}$ 11.771, de 17 de Setembro de 2008. Dispõe sobre a Política Nacional de Turismo, define as atribuições do Governo Federal no planejamento, desenvolvimento e estímulo ao setor turístico; revoga a Lei $\mathrm{n}^{\circ} 6.505$, de 13 de dezembro de 1977, o Decreto-Lei ${ }^{\circ}$ 2.294, de 21 de novembro de 1986, e dispositivos da Lei $\mathrm{n}^{\circ}$ 8.181, de 28 de março de 1991; e dá outras providências. Diário Oficial [da] República Federativa do Brasil, Brasília, DF - Seção 1 - 18 de set 2008, Página 1.

CARVAlHo, A. F. de. Políticas públicas em turismo no Brasil. Revista Sociedade e Cultura, Goiânia, v. 3, n. 1, p. 97-109, jan./dez. 2000.

CASTRO, A. T; NASCIMENTO, F. P. Regionalização do turismo no estado do Pará. In: ENCONTRO NACIONAL DOS GEÓGRAFOS, 2010. Anais XVI. Porto Alegre: Associação dos Geógrafos Brasileira, 2010. 13p. 
CRUZ, R. de C. A. da. Políticas de turismo e construção do espaço turístico -litorâneo no nordeste do Brasil, p. 263-272. In: LEMOS, A. I. G. de (Org.) Turismo: Impactos socioambientais. 3. ed. Editora Hucitec: São Paulo, 2001.

CUERVO, R. S. El turismo como medio de comunicación humana. Cidade do México: Departamento de Turismo do Governo do México. 1967

DE OLIVEIRA, T. M. A Lei do Turismo-Lei 11.771 de 17 de setembro de 2008: uma breve análise. Revista Turismo em Análise, v. 20, n. 2, p. 251-262, 2009.

DENCKER, A. de F. M. Métodos e técnicas de pesquisa em turismo. São Paulo: Futura, 1998.

EMBRATUR. Instituto Brasileiro de Turismo. Retratos de uma caminhada: PNMT 8 anos. Brasília: EMBRATUR, 2002.

FAPESPA. Fundação Amazônia de Amparo a Estudos e Pesquisas do Pará. Lançamento do boletim do turismo do estado do Pará 2016. Disponível em <file:///E:/apresentacao_boletim_de_turismo_versao_final30_03_2016_0.pdf>. Acesso em junho de 2016.

HALL, C. M. Planejamento Turístico: políticas, processos e relacionamento. 2. ed. São Paulo: Contexto, 2004.

LAGE, B.; MILONE, P. C. Economia do Turismo. 2 ed. São Paulo: Papirus, 1996.

LAKATOS, E. M.; MARCONI, M. de A. Fundamentos de metodologia científica. 6. ed., $7^{\mathrm{a}}$ reimpressão, São Paulo: Atlas, 2009.

LEIPER, N. Tourism systems: an interdisciplinary perspective. Palmerston North: Department of Management Systems, Massey University: Nova Zelândia, 1990.

MAMEDE, G. Direito do turismo: legislação específica aplicada. 2. ed. São Paulo: Atlas, 2002.

MARTINS, G. de A.; THEÓPHILO, C. R. Metodologia da investigação científica para ciências sociais aplicadas. 2. ed. São Paulo: Atlas, 2009.

MOLINA, S. Turismo: metodologia para su planificación. Cidade do México; Trilhas, 1997.

NÓBREGA, W. Turismo: planejamento e políticas públicas na Amazônia, Rio de Janeiro: E- Papers, 2007.

NORTH, D. C. Instituciones, cambio institucional y desempeño econômico. México: Fondo de Cultura Económica / Economía Contemporánea, 1995. 
OLIVEIRA, A. P. Turismo e desenvolvimento: planejamento e organização. 4. ed. São Paulo - SP: Editora Atlas, 2002.

OMT. Organização Mundial de Turismo. Guia de desenvolvimento do turismo sustentável. Tradução de Sandra Netz. Porto Alegre: Bookman, 2003.

PAIVA, M. das G. de M. V. Análise do Programa de Desenvolvimento do Turismo do Nordeste (Prodetur/NE) na perspectiva do planejamento estratégico. Revista de Administração Pública, Rio de Janeiro , v. 44, n. 2, p. 197-213, Abr. 2010.

PARÁ. Lei no 7.593, de 28 de dezembro de 2011. Cria o Sistema Estadual de Gestão do Turismo, a Secretaria de Estado de Turismo, e dá outras providências. Diário Oficial do Estado do Pará. Belém, PA, no 32.066, de 29 de dez 2011. Página 15.

. Companhia Paraense de Turismo. Plano de desenvolvimento turístico do estado do Pará. Belém: PARATUR, 2001.

Decreto $\mathbf{n}^{0}$ 1.066, de 19 de junho de 2008. Dispõe sobre a regionalização do Estado do Pará e dá outras providências. Diário Oficial do Estado do Pará. Belém, PA, nº 31.194, de 20 de jun 2008. Página 8.

Lei $\mathbf{n}^{0}$ 8.093, de 30 de dezembro de 2014. Autoriza a extinção da Companhia Paraense de Turismo- PARATUR, e dá outras providências. Diário Oficial do Estado do Pará, Belém, PA, No 32797, de 30 de dez 2014, Página 5.

Secretaria de Estado de Turismo. Plano Ver-o-Pará: Plano estratégico de turismo do Estado do Pará 2012-2010 Relatório Executivo. Belém: Secretaria de Estado de Turismo, 2011. Disponível em:

$<$ http://setur.pa.gov.br/sites/default/files/pdf/plano_ver-o-para.pdf $>$. Acesso em: 02/07/2016

PETROCCHI, M. Gestão de Pólos Turísticos. São Paulo: Futura, 2001.

QUEIROZ, L. A. de. O turismo baiano no Real e na competitividade internacional, Bahia Análise \& Dados, Salvador, v. 5, n. 3, dez. 1995.

SANSOLO, D. G. Políticas e planejamento do turismo na Amazônia. Caderno Virtual de Turismo, v. 13, n. 1, 2013.

SANTOS, G. E. de O.; KADOTA, D. K. Economia do Turismo. São Paulo: Editora Aleph, 2012.

TRIVIÑOS, A. N. S. Introdução à pesquisa em ciências sociais: pesquisa qualitativa em educação, positivismo, fenomenologia e marxismo. 1. ed. $20^{\mathrm{a}}$ reimpressão, São Paulo: Atlas, 2011.

VIGNATI, F. Gestão de destinos turísticos: como atrair pessoas para polos, cidades e países. Rio de Janeiro: Ed Senac, 2012. 
YIN, R. K. Estudo de caso: planejamento e métodos. 2. ed. tradução. Daniel Grassi. Porto Alegre: Bookman, 2001.

Recebido em: 27-06-2017.

Aprovado em: 27-06-2017. 